\title{
O Distrito Florestal do Vale do Jequitinhonha: uma análise a partir dos paradigmas
}

\section{e das narrativas}

\author{
The Jequitinhonha Valley Forest District: an analysis from paradigms and narratives \\ El Distrito Forestal del Vale do Jequitinhonha: un análisis desde los paradigmas y las narrativas
}

Recebido: 27/02/2021 | Revisado: 06/03/2021 | Aceito: 16/03/2021 | Publicado: 20/03/2021

Leonardo França da Silva

ORCID: https://orcid.org/0000-0002-9710-8100

Universidade Federal de Viçosa, Brasil

E-mail: leonardo.silva@ufv.br

Marcos Antônio Pereira da Fonseca Maltez

ORCID: https://orcid.org/0000-0003-0941-8051

Universidade Federal Rio Grande do Sul, Brasil

E-mail: marcos.maltez@biocitrus.com.br

Alexandro Moura Araújo

ORCID: https://orcid.org/0000-0002-9936-4650

Universidade Federal do Mato Grosso do Sul, Brasil

E-mail: alexx_m_a@ $@$ hotmail.com

Emília Pereira Fernandes da Silva

ORCID: https://orcid.org/0000-0002-9710-8100

Universidade Federal de Minas Gerais, Brasil

E-mail: emiliafernandes_pdi@ @otmail.com

Maria Angela de Souza

ORCID: https://orcid.org/0000-0002-1061-3340 Universidade Federal de Viçosa, Brasil

E-mail: maria.a.souza@ufv.br

Érika Manuela Gonçalves Lopes

ORCID: https://orcid.org/0000-0002-7518-8955

Universidade Federal de Minas Gerais, Brasil

E-mail: emglopesm@gmail.com

Rafaella Resende Andrade

ORCID: https://orcid.org/0000-0003-3182-0741 Universidade Federal de Viçosa, Brasil E-mail: rafaella.andrade@ufv.br

Osmar de Carvalho Bueno

ORCID: https://orcid.org/0000-0003-0666-090X Universidade Estadual Paulista, Brasil

E-mail: osmar.bueno@unesp.br

\begin{abstract}
Resumo
O presente estudo analisa o modelo de desenvolvimento proposto para a região do Vale do Jequitinhonha, localizado na porção noroeste de Minas Gerais. Foram avaliados, por meio da análise de narrativas de políticas públicas, documentos institucionais históricos efetivados durante o período da ditadura militar, atentando-se aos preceitos que legitimaram a ação estatal, principalmente, pelo incentivo à produção de eucaliptais, que culminaram com a criação do Distrito Florestal. Por meio das narrativas, observou-se que a doutrina vigente na época viabilizou o modelo desenvolvimentista baseado na produção monocultora, por meio de políticas de subsídios. Definidos os problemas e as soluções a serem atingidas, o que se observou é uma dicotomia ao se cruzar com as narrativas dos agricultores que ocupavam os espaços destinados ás políticas, o que permitem ponderar modelos de desenvolvimento sob o ponto de vista institucional e aqueles na visão do beneficiário.
\end{abstract}

Palavras-chave: Desenvolvimento; Políticas públicas; Agricultura familiar.

\begin{abstract}
The present study analyzes the proposed development model for the Jequitinhonha Valley region, located in the northwest of Minas Gerais. Through the analysis of public policy narratives, historical institutional documents were evaluated during the period of the military dictatorship, observing the precepts that legitimized the state action, mainly to encourage the production of eucalyptus, which culminated in the creation of the Forest District. Through the narratives, it was observed that the doctrine in force at the time made possible the model of development based on monoculture, through subsidies policies. In view of the problems and solutions to be reached, what was observed was a dichotomy if the narratives of the farmers who occupied the spaces for the policies were observed, which allowed to consider models of development from the institutional point of view and those in the view of the beneficiary.
\end{abstract}


Keywords: Development; Public policy; Family farming.

\section{Resumen}

El presente estudio analiza el modelo de desarrollo propuesto para la región del Vale do Jequitinhonha, situada en el noroeste de Minas Gerais. Evaluamos, a través del análisis de las narrativas de las políticas públicas, los documentos institucionales históricos efectuados durante el período de la dictadura militar, prestando atención a los preceptos que legitimaron la acción estatal, principalmente mediante el fomento de la producción de bosques de eucalipto, que culminó con la creación del Distrito Forestal. A través de los relatos, se observó que la doctrina vigente en la época permitía el modelo de desarrollo basado en la producción de monocultivos a través de políticas de subsidios. Una vez definidos los problemas y las soluciones a alcanzar, lo que se observó fue una dicotomía al cruzar con las narrativas de los agricultores que ocupaban los espacios destinados a las políticas, lo que permitió ponderar los modelos de desarrollo desde el punto de vista institucional y los de la perspectiva del beneficiario.

Palabras clave: Desarrollo; Políticas publicas; Agricultura familiar.

\section{Introdução}

O Rio Jequitinhonha nasce na Serra do Espinhaço, na cidade de Serro em Minas Gerais, e deságua no oceano Atlântico, na cidade de Belmonte na Bahia. A bacia tem extensão total de $70.315 \mathrm{~km}^{2}$, sendo que $96 \%$ fica em Minas Gerais. A mesorregião do Vale do Jequitinhonha fica localizada no noroeste do estado e é culturalmente e politicamente dividida em 3 microrregiões: o Alto, Baixo e Médio Jequitinhonha.

A região, em estudos anteriores, tornou-se amplamente estigmatizada como sendo local de extrema pobreza. Com um artesanato marcante, forte presença da agricultura familiar, e pelas organizações estruturais familiares em busca de melhores condições, alguns de seus membros migravam para outros Estados em determinados períodos do ano. Ao longo dos anos, técnicos e formuladores de políticas públicas procuraram entender e resolver os problemas relacionados aos baixos índices de desenvolvimento na região, sendo que uma das soluções vislumbradas, na época, foi tornar a região alvo de grandes projetos (monoculturas, barragens e mineração). Esses projetos pretendiam levar desenvolvimento à região e, apesar de serem diferentes, se coincidiam em alguns aspectos: utilizavam-se das vantagens propiciadas por ambientes considerados "esquecidos", cujas decisões passavam longe do crivo da própria população. Dessa forma, os benefícios gerados com a sua implementação raramente se converteram em favor dos moradores dessa localidade.

Entre os projetos que propunham o desenvolvimento da região, as monoculturas de eucalipto, talvez, sejam as que mais chamam atenção. Hoje, existe, aproximadamente, 400.000 hectares de florestas de eucalipto na região (Calixto, 2006). Esse processo denominado de Distrito Florestal do Vale do Jequitinhonha (DFVJ) é fruto das políticas que chegaram à região como "salvacionistas" para os problemas de subdesenvolvimento ali presentes. Este artigo tem como objetivo discutir a criação do DFVJ, a partir da abordagem cognitiva de análise de políticas públicas, em especial os paradigmas e as narrativas que influenciaram.

A análise por meio dos paradigmas de políticas públicas teve como principal autor Peter Hall. Este autor propõe estudar as políticas públicas a partir das crenças comuns que guiam os conjuntos de atores, sejam eles privados ou públicos. Essas crenças vão definir a maneira como estes atores interpretam os problemas e criam soluções para os mesmos (Hall, 1993). Neste trabalho, propõe-se analisar os paradigmas referentes ao período da ditadura militar (1964-1985). Na segunda parte, o artigo foca no estudo das narrativas que legitimaram as ações do Estado na região.

\section{Metodologia}

A presente pesquisa compreende-se como de natureza qualitativa, sendo nesta recorrente uma "interpretação por parte do pesquisador com suas opiniões sobre o fenômeno em estudo" (Pereira et al., 2018, p. 67). Para a realização do estudo, foi utilizada a técnica de análise de narrativas de documentos históricos de diferentes instituições que ajudaram a construir o Alto Jequitinhonha, enquanto plano de ação do Estado. A utilização da técnica analítica de documentos, registros, cartas, entre 
outros, possibilitam a coleta de informações importantes em pesquisas (Pereira et al., 2018).

O marco teórico da análise de narrativas políticas (Narrative Policy Framework - NPF) compreendem, enquanto um campo de pesquisa empírico, num fenômeno recente da ciência, datando seu início em meados dos anos 2000 (Vasconcelos, 2018; Rodrigues Neto \& Barcelos, 2020). Em uma revisão sistemática com 45 artigos voltados para os processos políticos, Lamba, Silvestre e Correia (2019) não identificaram nenhum estudo com a aplicação desse framework teórico.

As narrativas políticas podem ser entendidas como um conjunto de discursos, que são consideradas verdades pelos atores e que tentam, de alguma forma, influenciar na formação, implantação, instrumentação e avaliação de agendas em políticas públicas. As narrativas são formadas por histórias com vilões, heróis, início, meio e fim, as quais são responsáveis por relatar, nem sempre em exatidão, as causas e soluções de um problema em determinado período ou lugar (Grisa, 2011; Lopes, 2015).

As narrativas são essenciais nas políticas, elas se tornam o resultado visível das diferenças em crenças políticas (Lopes, 2015). As análises das narrativas políticas devem se basear na estrutura própria que elas constroem. Rodrigues Neto e Barcelos (2020) destacam que os componentes estruturais constantes para a construção das narrativas políticas são o cenário, o roteiro, os personagens e a moral da história. De acordo com Lopes (2015) e Rodrigues Neto e Barcelos (2020), essas estruturas se diferenciam, sendo que:

1. O contexto define geograficamente, institucionalmente ou culturalmente o contexto em que a narrativa vai se formar.

2. O enredo/roteiro explica as relações entre os componentes da história e as explicações que determinam a veracidade da narrativa.

3. Os personagens desempenham uma função importante no entendimento das narrativas. Podem ser grupos de interesses, ONGs, associações, etc. Esses personagens podem variar em suas características específicas, mas são teorizados para ocupar uma das três categorias gerais: heróis (e aliados), vilões (e inimigos) e vítimas.

4. A moral da história aparece como uma solução dos problemas, apresentando-se na forma de uma política pública.

Por fim, no que tange ao NPF, cabe ressaltar a existência de 03 níveis de análise: "o nível micro refere-se à influência das narrativas de política nos indivíduos; o nível meso examina a influência das narrativas em coalizões de política; e o nível macro examina as narrativas em contextos culturais e institucionais amplos" (Rodrigues Neto \& Barcelos, 2020, p.1637).

A aplicação da análise de narrativas políticas pode ser encontrada em pesquisas que contextualizam a realidade brasileira. No estudo desenvolvido por Vasconcelos (2018), por exemplo, analisou-se as narrativas políticas de segurança alimentar, através de um conjunto de 34 relatórios globais da Organização das Nações Unida para Alimentação e Agricultura (FAO), e em entrevistas com atores chaves de organizações brasileiras e estrangeiras. Em seguida, classificou-os com base em"quatro paradigmas políticos diferentes, sendo eles, o Neomalthusiano, o Neoliberal, o Seniano e o NovoDesenvolvimentista" (Vasconcelos, 2018, p. 168). A autora identificou a presença de variados paradigmas nas narrativas de segurança alimentar pela FAO/ONU, considerando-se os períodos, a gestão e a adoção das metas globais (ou os Objetivos do Desenvolvimento Sustentável - ODS).

No estudo de Teixeira et al (2020), buscou-se analisar as políticas e ações adotadas pelo Estado brasileiro, durante a pandemia, sob a luz do NPF. A Inação política foi vista nas narrativas construídas durante a pandemia, ao observar a falta de estreitamento no jogo político, com outros governantes em prol de uma mesma causa; a reduzida aplicação de recursos para a saúde, o controle sobre os gastos públicos para a saúde e de socorro aos empreendimentos, e os distúrbios com outras potências 
políticas mundiais, enviesado por um plano ideológico, sobre como deveria ser conduzido as políticas públicas de combate ao Covid-19 (Teixeira et al., 2020).

Rodrigues Neto e Barcelos (2020) contextualizaram as narrativas políticas, relacionadas a produção de uma agenda de políticas públicas numa Instituição Federal de Ensino, voltadas para ações afirmativas étnico-raciais. Através da coleta de documentos, como atas, normais e regulamentações oficiais e entrevistas, os autores observaram a presença dos componentes de narrativas do NPF, na medida que estas foram influenciando a construção de agendas sobre esse tema.

Relacionando-se o NPF em contextos de políticas agroalimentares, Silva e Anjos (2020), através da realização de entrevistas com 27 participantes atores, analisaram sob a luz do NPF, a expansão da soja e seus impactos ao ambiente em uma região do RS, observando a conveniência relacionada a regulação da produção. As narrativas indicaram incongruências, quando observado os aspectos socioambientais, sobre a noção de regulação/controle produtivo, os benefícios fiscais, e a importância para a flexibilização e adoção de equipamentos mais modernos, tanto pelo setor quanto pelo poder público.

Grisa (2018), por outro lado, indica a existência de narrativas interligadas a referenciais globais/setoriais, isto é, as percepções gerais relacionadas a sociedade, e que se vinculam com a agricultura familiar no País. A autora identificou a existência de "novas" narrativas atreladas ao controle de gastos públicos, que refletindo-se nos agentes econômicos e na figura do Estado, alteraram a relação de atores já envolvidos na pauta agrícola familiar brasileira, cuja substituição da mediação, por ora, se desvincularam com os ideais anteriores, propostos pelo extinto Ministério do Desenvolvimento Agrário. A transferência e a dissolução de pautas relacionadas, como o aspecto social nos sistemas agroalimentares, para outras secretarias, minimizaram as discussões e o poder político, que vinha sendo construídas, sobre o papel da produção familiar. A redução de políticas públicas de acesso à água, assistência técnica e extensão rural, renda, reforma agrária, deram novas interpretações no campo da política neoliberal, no contexto agrícola familiar.

As narrativas identificadas no estudo de Niederle et al. (2019) se aproximam com Grisa (2018), analisando as mudanças ocorridas nas políticas relacionadas ao desenvolvimento da agricultura familiar brasileira, ao longo do tempo. Niederle et al. (2019) destacaram i) a identificação das unidades familiares e sua participação no abastecimento alimentar da população; ii) o surgimento de uma narrativa conservadora pautada entre capacidades produtivas e não-produtivas agrícolas e seu valor bruto, após a atuação do MDA, como forma de desqualificação da agricultura familiar; iii) a identificação de produtores médios (que não se enquadravam na categorização do MDA); iv) a percepção de uma agricultura eficiente como uma "nova narrativa" entre ser avançado ou atrasado/irrelevante tecnologicamente; e v) a supressão de recursos públicos, que culminou com a extinção de políticas do MDA, voltados para as unidades familiares, como o crédito, assistência/extensão e a reforma agrária.As narrativas no presente estudo foram retiradas de documentos históricos que foram produzidos por instituições federais e estatais, as quais tinham como foco de trabalho a região do Jequitinhonha. Esses documentos, em geral, se resumiam em planos integrados de desenvolvimento para a região, mas, para analisar as narrativas que auxiliam a entender como toma forma Distrito Florestal do Vale do Jequitinhonha, foi preciso buscar documentos produzidos por diferentes instituiç̃oes, que, a partir da sua área de atuação, vão criar um cenário propício para a implantação do DFVJ.

As narrativas como metodologia para análise de políticas públicas permitiram fornecer instrumentos adequados para responder as questões deste trabalho. Os paradigmas forneceram instrumentos para compreender como a conjuntura nacional entendia os problemas gerais da nação e propunha soluções para estes. Por sua vez, o estudo das narrativas forneceu material para esclarecer como os paradigmas dominantes da época foram legitimados na região do Jequitinhonha e, diretamente, influenciaram na construção das políticas para o desenvolvimento da região, em específico a formação do DFVJ. 


\section{Resultados e Discussão}

Visando tornar a compreensão dos resultados mais precisa, inicialmente foi efetuado a contextualização sobre o modelo aqui adotado para análise das políticas públicas. Em seguida, efetuou-se a descrição das principais narrativas de desenvolvimento das instituições incentivadoras e atuantes no Vale Jequitinhonha, para, por fim, serem observadas as principais narrativas tanto do ponto de vista da política, quanto dos seus paradigmas, sob um olhar enquanto Distrito Florestal.

\section{Paradigmas e Políticas Públicas}

A principal referência teórica dessa metodologia de análise de políticas públicas foi desenvolvida por Peter Hall. O pesquisador se propôs a estudar a relevância e o impacto dos paradigmas nos processos de aprendizagem social, os quais acompanham o desenvolvimento e as mudanças das políticas públicas (Hall, 1993).

De modo muito simplificado, o modelo proposto repousa, antes de tudo, sobre a convicção de que existem valores e princípios gerais que definem isso que se poderia chamar de "uma visão de mundo". Trata-se, no caso, de princípios abstratos, que definem o campo dos possíveis e do dizível numa sociedade dada, identificando e justificando a existência de diferenças entre indivíduos e/ou grupos, hierarquizando um certo número de dinâmicas sociais (Muller \& Surel, 2002, p. 42).

O autor explora, no seu trabalho, o relacionamento entre as ideias políticas e a configuração institucional e abrange de forma cognitiva como as ideias mediam os resultados políticos. Discute, ainda, como o peso das ideias e as ações das instituições interagem entre si, formando, assim, contextos específicos que permitem a produção de mudanças nas políticas (Hall, 1993).

Portanto, a partir destas ideias, serão definidas as políticas que deverão enfrentar os problemas percebidos como centrais para a área, assim sendo os paradigmas, que as orientam, identificarão quais resultados deverão ser perseguidos por meio dessas (novas) políticas públicas e quais métodos as farão alcançar a meta estipulada (Lopes, 2015 , p. 6).

Os elaboradores de políticas públicas detêm suas estratégias de trabalho baseadas em um conjunto de ideias e normas, as quais vão orientar como estes interpretam os problemas e criam soluções. Esta forma comum de admirar um problema/solução é nomeada de paradigma de uma política pública (Grisa, 2011). De acordo com Hall (1993), em discussões técnicas complexas (como o caso das elaborações de políticas públicas), os formuladores são, em sua maioria, direcionados por um conjunto de ideias, cujas origens e construções partem do aprendizado social.

Hall (1993) propôs um aprofundamento analítico que visa a divisão e diferenciação dos níveis de aprendizado social. O autor cita três ordens de aprendizado social que são ordens nas mudanças ocorridas nas políticas públicas. A primeira ordem compreende que as "condições específicas dos instrumentos de políticas são modifícadas, enquanto os próprios instrumentos e objetivos amplos são mantidos". A segunda ordem "altera o contexto e os instrumentos utilizados, embora se mantenham os objetivos iniciais". E, a terceira ordem corresponde a mudança no próprio paradigma político, logo, uma mudança no processo de construção das políticas públicas.

O aprendizado social, na análise de paradigmas, é utilizado para explicar as mudanças nas políticas públicas, representando as alterações nos pensamentos e formas de interpretação do mundo que são resultados de experiências e novas informações adquiridas pelos atores. Esse aprendizado modifica a forma como os atores vão interpretar e solucionar problemas que existem na sociedade. As mudanças nos paradigmas podem ser explicadas por acontecimentos de grande escala (crises 
econômicas, ambientais, mudança de governo), os quais vão mudar o paradigma de forma rápida, ou então essa mudança pode se dar de forma progressiva e sutil, sendo o paradigma modificado ao longo de vários anos (Hall, 1993).

Portanto, numa palavra, é o conjunto dos elementos que fazem sistema, que levanta assim mapas mentais particulares. $\mathrm{O}$ interesse heurístico de distinguir estes diferentes componentes repousa, essencialmente, sobre o fato de que eles permitem isolar, analiticamente, os processos pelos quais são produzidas e legitimadas as representações, as crenças e os comportamentos, principalmente sob a forma de políticas públicas particulares no caso do Estado (Muller \& Surel, 2002, p. 47).

Essa forma de análise das políticas tem ênfase no modo como os atores compreendem o seu local, interpretam e propõem soluções aos problemas existentes. Os paradigmas, então, podem ser compreendidos como, em um determinado espaço de tempo, os atores (públicos e privados) entendem os problemas públicos e criam soluções para determinado local que estes estão envolvidos. A crença comum de formuladores de políticas em um determinado sistema político, econômico e/ou social cria uma ferramenta importante que influencie de forma direta o processo decisório de ação do Estado (Hall, 1993; Muller \& Surel, 2002; Grisa, 2011).

O período da ditadura militar (1964-1985) será utilizado como recorte histórico para a análise dos paradigmas relacionados ao desenvolvimento que influenciaram na formação do DFVJ. O golpe militar pode ser entendido como uma mudança no paradigma, que acontece a partir de um evento de grande escala, como a tomada do poder pelos militares através de um golpe. Essa mudança altera o conjunto de atores, instituições e, principalmente, as ideias que guiavam as formulações das políticas públicas.

Os objetivos para além do golpe ainda eram vagos, o levante não foi dado com o objetivo de indicar alguém ao poder e não apresentava um projeto claramente definido (Soares, 1994; Fico, 2004; Fagundes, 2014). Para a continuidade no governo era necessária a construção de um novo regime e de mudanças nos rumos da política e da economia, além da propagação de um discurso que garantisse legitimidade desses processos. A chamada Escola Superior de Guerra (ESG), em 1964, já havia criado esse discurso e foi fundamental na formulação de políticas públicas nesse período (Fagundes, 2014).

A ESG foi fundada em 1948, ainda sobre impacto da Segunda Guerra Mundial e teve forte influência do Exército dos Estados Unidos da América. Os militares brasileiros ficaram impressionados com o poder organizacional e bélico dos americanos. Assim, no intuito de criar um laboratório de ideias para o projeto "Brasil Potência" fundaram a ESG, que elaborou a Doutrina de Segurança Nacional e Desenvolvimento, cuja base de autores compreende a sociologia positivista e o anticomunismo (ESG, 1976; Fagundes, 2014).

Dessa forma, a ESG tinha suas bases ideológicas ligadas ao internacionalismo, liberalismo econômico, política externa alinhada com os Estados Unidos e manutenção das instituições políticas como o parlamento e os partidos. A ESG representa um importante papel não apenas como "Think Thank Militar", mas também como importante multiplicador da sua doutrina pelo resto do país. Além disso, exerce papel fundamental nas políticas que foram desenvolvidas durante a ditadura, de modo que as ações do Estado estão fortemente relacionadas às interpretações do mundo que a escola propunha, principalmente quando se refere a chamada Doutrina de Segurança Nacional e Desenvolvimento, a qual direciona boa parte dos esforços da ditadura militar (Calixto, 2006; Fagundes, 2014).

A Doutrina de Segurança Nacional e Desenvolvimento seria "uma síntese política, econômica, social e de estratégia militar". Era influenciada pela tecnocracia, baseada em uma confiança na capacidade da ciência e tecnologia resolver os problemas econômicos e sociais do país. Assim, era atribuída aos técnicos a competência de solucionar os problemas de desenvolvimento (Uran Apud Calixto, 2006). 
De acordo com isto, Hall (1993) chama atenção de que em campos tecnicamente complexos (como no caso das políticas públicas), os formuladores são guiados por um conjunto amplo de ideias que são retiradas dos aprendizados das partes interessadas. Neste caso, a aprendizagem vem da forte influência da escola americana, cuja ajuda se deu no processo de formação e inspiração da ESG.

Com a ditadura, o Brasil passou a ter um plano de desenvolvimento atrelado à ideia de crescimento econômico, sendo esse o objetivo fundamental. $\mathrm{O}$ desenvolvimento, nesse sentido, era considerado como uma peça-chave para a segurança do território brasileiro, através da utilização dos recursos considerados mínimos para o seu desenvolvimento, sem a necessidade de importação de elementos considerados fundamentais para o crescimento da indústria brasileira, principalmente entre 1972 e 1974.

No tocante a insumos básicos, adotará o Brasil uma política de garantia de suprimento sempre que viável, objetivando a auto-suficiência, e, muitas vezes, a abertura de fluxo de exportação: quando inviável a auto-suficiência, procurará reduzir ao mínimo a dependência em relação a fontes externas, inclusive associando-se a empreendimentos binacionais ou multinacionais para garantia de oferta, em condições razoáveis.

Em sentido amplo, são os seguintes os principais grupos de insumos básicos considerados:

\section{- Produtos siderúrgicos e suas matérias primas}

- Metais não ferrosos e suas matérias primas

- Produtos petroquímicos e suas matérias primas

- Fertilizantes e suas matérias primas

- Defensivos agrícolas e suas matérias primas

- Papel e celulose (...) (Brasil, 1971, p. 48)

A política adotada tinha como objetivo a substituição das importações, redução da dependência externa e a estatização dos setores básicos de economia. As empresas estrangeiras faziam investimentos em setores de alta tecnologia como produtos químicos, farmacêuticos e insumos agrícolas, ficando o Estado responsável pela criação da infraestrutura necessária para o desenvolvimento da indústria, favorecendo processo de internacionalização da economia e privilegiando o modelo de associação com o capital estrangeiro. Para atingir os objetivos do modelo de desenvolvimento, que o regime militar se orientou, foi incentivado o alto padrão de consumo de bens duráveis, o que favorecia indústrias produtoras desses bens e suas fornecedoras de matérias primas (Calixto, 2006).

A cadeia siderúrgica era entendida como fundamental para o desenvolvimento do país. Esse tipo de indústria seria responsável pelo abastecimento das indústrias de bens de consumo duráveis e deveria ser nacional, a fim de que a dependência externa de matéria prima, por parte das indústrias de bens duráveis, fosse mínima. O crescimento econômico da época provocaria o aumento na demanda por aço devido ao crescimento industrial (Calixto, 2006). A siderurgia foi bastante incentivada durante o período militar, sendo criado um plano governamental especialmente dedicado a expansão desse segmento: o Plano Siderúrgico Nacional (PSN), que foi elaborado em 1967.

A siderurgia utilizava o "coque", um carvão mineral derivado do petróleo, para o beneficiamento do aço, porém, com a crise do petróleo, outras alternativas energéticas tiveram que ser pensadas. O plantio de eucaliptos para a produção de carvão passou a ser cogitado como "a única via tecnológica comprovada e economicamente viável, independente de fontes energéticas importadas" (Calixto, 2006). Assim, a autora destaca que o emprego do carvão, portanto, tornou-se um atrativo energético para as indústrias nacionais, considerando que diversas empresas além de usufruir, tiveram bases de apoio por parte do governo 
para fomentar a produção, como forma de viabilização energética e financeira ao setor, através da criação dos distritos florestais.

O desenvolvimento atrelado a produção de bens de consumos duráveis, com alta dependência de eucalipto para a produção de carvão, exige do governo a criação de planos para fomentar o investimento em áreas de reflorestamento. Uma solução encontrada foi a promulgação da Lei $n^{\circ}$ 5.106, de 2 de setembro de 1966. Essa lei era referente "as importâncias empregadas em florestamento e reflorestamento que poderão ser abatidas ou descontadas nas declarações de rendimento das pessoas físicas e jurídicas, residentes ou domiciliados no Brasil, atendendo às condições estabelecidas na presente lei”. O estímulo fiscal era dado às atividades referentes a

"despesas de florestamento e reflorestamento aplicadas diretamente pelo contribuinte ou mediante a contratação de serviços de terceiros, na elaboração do projeto técnico, no preparo de terras, na aquisição de sementes, no plantio, na proteção, na vigilância, na administração de viveiros e flores e na abertura e conservação de caminhos de serviços" (Brasil, 1966).

A criação dessa lei dá início à implementação de empreendimentos em várias partes do país, sendo Minas Gerais o estado que mais recebeu investimentos em monoculturas de eucaliptos. O Vale do Jequitinhonha, nessa época, era uma região considerada estagnada economicamente, de agricultura camponesa e pouco ligada aos mercados externos. Essa situação ia totalmente contra o projeto de Brasil do regime militar, o que levou à criação de diversos projetos de desenvolvimento para a região. Assim, esses projetos estavam pautados nas ideologias da Doutrina de Desenvolvimento e Segurança Nacional.

Edmundo Coelho (2000) sintetizou 8 conjuntos de ideologias que seriam postulados base para a doutrina:

a) os indivíduos só valem pelo que realizam em conjunto e em benefício do conjunto; b) uma comunidade em que o bem coletivo está acima dos interesses dos indivíduos e dos grupos possui uma vida moral mais elevada; c) o Estado é o instrumento de mobilização da ação coletiva e a lealdade para com o Estado deve ter precedência sobre as demais; d) a centralização do poder é indispensável como garantia da unidade nacional; e) as áreas de consenso devem superar por larga margem as do dissenso para que a sociedade nacional seja viável; f) a função da elite dirigente é educativa por excelência e a ela cabe definir os interesses da coletividade, já que faltam aos indivíduos as condições de identificá-los; g) o desenvolvimento econômico é um objetivo fundamental; h) a tarefa de promover o desenvolvimento econômico cabe à nação como um todo e requer disciplina, austeridade, sacrifícios e renúncias por parte dos grupos e indivíduos (Coelho, 2000).

Esses conjuntos de ideias que orientavam a Doutrina da Segurança Nacional e Desenvolvimento iriam, então, influenciar as ações do estado na política, economia e desenvolvimento. Considerando-as, para o caso do Vale do Jequitinhonha, três postulados talvez sejam a exteriorização de como esses paradigmas atuaram na formulação de políticas públicas: 1) caberia a elite a identificação dos interesses coletivos, considerando que os mesmos não se "mostravam" capacitados; 2) o crescimento da economia seria desenvolvida à outrance; 3) os benefícios à economia brasileira requeria sacrifícios, controle e rigidez por parte do seu povo.

O Vale do Jequitinhonha se apresentava (e ainda se apresenta) extremamente rural, com forte presença da agricultura camponesa. O rural esteve nesse período (e ainda é) associado à ideia de subdesenvolvimento, atraso econômico e pobreza (Ribeiro, 2007), onde os agricultores não teriam a capacidade das resoluções dos seus próprios problemas e caberia ao estado levar desenvolvimento e industrialização à região. A agricultura que era praticada estava longe de ser um "modelo ideal” pelos tecnocratas que a consideravam arcaica e rudimentar.

A agricultura familiar da região se desenvolveu criando formas específicas de uso dos recursos naturais. No Alto Jequitinhonha, as populações rurais utilizavam duas paisagens predominantes: “chapadas e grotas”. As chapadas eram regiões de uso comum, em que os agricultores criavam gado a solta e coletavam frutos e plantas medicinais. Já, as grotas são terrenos 
com a declividade mais acentuada, porém apresentam uma melhor fertilidade do solo, sendo, nessas áreas, que os agricultores faziam seus roçados, hortas, pomares e criações de pequeno porte.

A utilização das terras dessa maneira passava a impressão de uso ineficaz dos recursos naturais, onde as populações rurais, com suas técnicas, não conseguiam fazer a exploração correta dos recursos naturais disponíveis. Assim, essa ocupação e exploração da terra, sendo totalmente diferente do paradigma pregado na época, propiciava ao governo o entendimento de que tais áreas eram despovoadas com pouca ou nenhuma serventia (Calixto, 2006) e, então, sendo terras "abandonadas", os eucaliptais eram implementados.

Nessa época, tomam força, no Brasil e no mundo, os processos de modernização da agricultura, a partir dos pacotes tecnológicos da chamada Revolução Verde. Esse movimento previa uma adaptação e o emprego de sementes com diferentes qualidades genéticas e equipamentos de alta geração, visando ao aumento da produção de alimentos em larga escala, garantindo a redução dos custos da produção agrícola.

Naquele período, visando capitalizar recursos privados e públicos, por meio da modernização da produção alimentar, recebeu um apoio do regime militar. O II Plano Nacional de Desenvolvimento (II PND - de 72 a 74), descreve essa movimentação:

Se faz necessário que a agricultura e a pecuária passem a desempenhar um novo papel na estratégia nacional de desenvolvimento. Tem se assinalado que o Setor Agropecuário, nos anos 60 e 70, vêm revelando dinamismo, razoável capacidade de reação a estímulos e desempenho satisfatório das suas funções (...). Trata-se, agora, de exigir muito mais do setor agropecuário e efetivar a vocação do Brasil como supridor mundial de alimentos, matérias primas agrícolas e produtos agrícolas industrializados (Brasil, 1971, p. 55).

O novo modelo de agricultura ocasionou uma forte mudança na forma de entender e fazer agricultura. Assim, tornar a agricultura como inovadora requeria o emprego de modelos atuais de produção, sementes, equipamentos. Isso provocou uma percepção de que os modelos, até então considerados tradicionais, e desenvolvidos em pequena escala por comunidades rurais, passassem a ser vistos como retrógrados, sem impacto para o desenvolvimento econômico e para o abastecimento nacional de alimentos; portanto, que poderiam (ou deveriam) ser readaptados. Esta também foi responsável pela viabilidade técnica da implantação do DFVJ e demais projetos agrícolas no cerrado, principalmente quando se descobriu que o maior problema da agricultura no cerrado não era relacionado a questão da água, como sempre foi pensado, mas, sim, devido à baixa fertilidade dos solos, o que pode ser resolvido com o pacote tecnológico.

Essa mudança na agricultura pode ser um exemplo enquadrado no que Hall (1993) chama de aprendizado social, o qual se dá a partir de experiências passadas ou externas da percepção de problemas sociais, podendo, também, ser fruto de pesquisas em novas ideias para solucionar problemas e de experiências passadas em ações do Estado. A revolução verde agregava-se à visão de desenvolvimento que pregava a ditadura militar, cujo desenvolvimento se daria a partir do crescimento econômico e seria coordenado a partir das elites do país.

As políticas direcionadas para a região baseavam-se na ideia do desenvolvimento tecnocrata, em que a formulação de políticas públicas tinha sua gênese no processo top-down, de forma que as características e especificidades da população, clima, relevo, economia e cultura não eram levadas em conta e/ou não tinham importância. Visto como um vazio cultural, educacional e de infraestrutura, o Vale do Jequitinhonha era considerado uma ilha parada no tempo, onde não existia energia elétrica, estradas, meios de comunicação e desenvolvimento.

Durante esse período, muitas políticas vão ser direcionadas para o Vale do Jequitinhonha seguindo os paradigmas da época. Essas políticas surgem a partir da interpretação de alguns problemas que deveriam ser resolvidos. Tanto o entendimento 
dos problemas, quanto a resolução vão repousar sobre os paradigmas dominantes da época. A ideia era, principalmente, levar desenvolvimento a região e em conjunto atender a agenda econômica do país.

\section{A Codevale e o Vale do Jequitinhonha}

A Comissão de Desenvolvimento do Vale do Jequitinhonha (CODEVALE) foi uma autarquia criada em 1964, atuante em 52 municípios, definidos por este órgão como a "região do Vale do Jequitinhonha". A autarquia tinha como objetivo agenciar a articulação entre os poderes públicos e a sociedade civil, afim de "promover o desenvolvimento socioeconômico da bacia mineira do Jequitinhonha" (Codevale, 1967). Assim, ficaria encarregada de produzir planos de ação para o Vale do Jequitinhonha que deveriam ser aprovados pelo governador. Como principal trabalho de diagnóstico, a CODEVALE produziu o Pré-diagnóstico do Vale do Jequitinhonha, que é dividido em duas partes: "O espaço físico e a realidade infraestrutural" e "Os setores básicos da atividade humana" (Codevale, 1967).

O presente trabalho é simplesmente a ordenação e adaptação dos estudos setoriais preparados pela equipe técnica da Comissão de Desenvolvimento do Vale do Jequitinhonha. Constitui, portanto, instrumento capaz de dar ao programador uma visão abrangente da região, proporcionando elementos necessários à tomada de posição de órgãos públicos e do setor privado face aos problemas do nordeste mineiros (Codevale, 1967, p. 10).

Esse pré-diagnóstico é usado como base para atuação do poder público na região e teve como objetivo analisar os principais problemas em relação ao desenvolvimento do Vale do Jequitinhonha:

Um dos primeiros passos da CODEVALE foi tornar possível o conhecimento da região, ao mesmo tempo que procurou diagnosticar, dentro de sua área de ação, os principais obstáculos ao desenvolvimento socioeconômico de uma das regiões potencialmente mais ricas do estado (Codevale, 1967, p.8).

No seu primeiro volume, o diagnóstico abordou questões relacionadas a localização, aspectos físicos, formação histórica, infraestrutura econômica (estradas, comunicação e energia) e infraestrutura social (educação, saúde, saneamento básico, associativismo, situação alimentar e renda). O principal empecilho, segundo o relatório, era a ausência de infraestrutura (social e econômica) que impedia o seu desenvolvimento e inserção da região na agenda de desenvolvimento do país.

Considerando que era extremamente necessária a implantação de infraestruturas econômicas para a viabilização de projetos na região, os diagnósticos colocavam grande peso no investimento para infraestrutura para levar desenvolvimento para a região. Os levantamentos apresentados são separados em energia, estradas e comunicações, sendo explanados os dados de pesquisas secundárias e realizadas a campo. Os resultados relacionados à energia são "sombrios" com pouquíssimas cidades abastecidas.

As conclusões obtidas do levantamento da atual situação energética do Vale do Jequitinhonha são, realmente, as mais sombrias. Os precários sistemas concentram-se, exclusivamente, no atendimento das sedes dos municípios. Não há qualquer produção de energia para o abastecimento do consumidor rural, estes que representam $76 \%$ da população rural (Codevale, 1967, p.50).

Por sua vez, a ausência de energia é, segundo o diagnóstico, um dos principais responsáveis pela falta de interesse em investimento na região. Também, um dos principais fatores que atrasam o desenvolvimento local, cuja dependência se dá a suas estruturas básicas de criação de gado e agricultura de subsistência.

A ausência de energia elétrica afasta a possiblidade de atração e sustentação de atividades econômicas em condições de promover, através do efeito multiplicador, o surgimento de uma nova estrutura econômica. A energia elétrica 
representa um dos fatores que irão permitir esta diversificação, atraindo para a região a atenção do empresariado. Não há energia porque não há mercado, não há mercado porque não há energia (Codevale, 1967, p.55).

O diagnóstico segue apresentando cálculos e gráficos de demandas e possibilidades para o mercado energético na região. Uma das alternativas seria construir parcerias entre as empresas estatais e privadas de energia e também a realização de um estudo sobre as possibilidades de utilização dos rios da região como geradores de energia. A questão energética é fundamental para o desenvolvimento, sendo pensado para o abastecimento rural e urbano.

No ponto sobre as estradas, o relatório coloca o Vale do Jequitinhonha como um "vazio" de rodovias, apresentando ligações com apenas algumas rodovias federais. A maior responsabilidade por isso era do Departamento de Estradas de Rodagem (DER), que utiliza os seguintes critérios para viabilizar a construção de estradas: fluxo de produção, fluxo de consumo e fluxo de transporte. Isto atrasava o desenvolvimento do Jequitinhonha, já que a região não apresentava, segundo as exigências do DER, os critérios necessários para construção de estradas (Codevale, 1967).

Isto, entretanto, não afasta a possibilidade de novas reivindicações, pois o quadro atual da Bacia do Jequitinhonha, e de um completo estágio de subdesenvolvimento, necessita de novos padrões, dentro dos quais possa ser vislumbrado no contexto estadual, nos meios de comunicação e, mais particularmente, nas estradas de rodagem transitáveis, sendo os melhores veículos para que se alcancem aqueles objetivos (Codevale, 1967, p. 74).

Se, pelas características econômicas, não seria viabilizada a construção das estradas, esta necessitaria ser feita pelo fator social, já que deveriam atender diretamente ao "homem do Jequitinhonha", como meta prioritária para o desenvolvimento da região (Codevale, 1967).

No que se refere as comunicações, o relatório mostra a região com uma ilha dentro de Minas Gerais, com apenas 2 cidades possuindo linhas interurbanas e 22 municípios com agência postal eletrônica. Sendo que esta é a menor do relatório e não traz resoluções para o problema. Nela, é ressaltada que alguns municípios vêm tentando, a partir de ações públicas e privadas, criar redes municipais de comunicação, mas que esse "processo é geralmente lento e de pequeno alcance" (Codevale, 1967).

O sistema de comunicações do Vale do Jequitinhonha é extremamente deficiente, sendo que, em termos de telefones interurbanos, a região pode ser considerada como uma ilha, já que apenas duas cidades - Bocaiuva e Diamantina, ambas situadas no Alto Jequitinhonha, possuem rede de telefone interurbano (Codevale, 1967, p. 77).

Após apresentar a infraestrutura econômica, o relatório apresenta o que ele chama de infraestrutura social. Nesse ponto, ele aborda questões referentes a educação, saúde e saneamento básico, renda e habitação, que são elementos básicos para conceber um desenvolvimento integrado da região, uma vez que essa infraestrutura será essencial para a mobilização e preparação dos trabalhadores disponíveis para serem incorporados pelos investimentos futuros na área. O volume II do Prédiagnóstico, denominado "Os setores básicos de atividade humana", tem como foco a análise das condições da agricultura e da pecuária que são realizadas no Vale do Jequitinhonha. O relatório sugere que as técnicas agrícolas que são utilizadas no Jequitinhonha são arcaicas e primitivas.

Assim, o relatório apresenta os problemas relacionados ao "rendimento reduzido" ou ao "baixo padrão de vida da população rural no Jequitinhonha”, problemas esses, que vinham sendo demonstrados no volume I do relatório. Esse documento propõe, então, que o caráter deficitário do rendimento agrícola da região é culpa dos agricultores "famintos e ignorantes" e não debate, em momento algum, a distribuição fundiária e a exploração desses agricultores por grandes fazendas (Codevale, 1967; Leite, 2010).

Agricultura rotineira e tradicional dos caboclos, pelo sistema de roças e coivaras, derrubando e queimando a mata para plantar uns poucos produtos agrícolas (milho, feijão, mandioca). Os instrumentos agrícolas são rudimentares tais como foices, machados e enxadas, o que faz com que a área cultivada, em geral, seja reduzida, limitando-se à 
capacidade de produção da força bruta do homem. A adubação ou outra prática agrícola racional são inteiramente desconhecidas, abandonando-se a área cultivada quando se manifestam sinais de exaurimento do solo, para derrubar uma nova área da mata. Tem-se assim, na sua forma mais atrasada uma rotação de terras, isto é, em lugar de haver uma rotação de culturas na mesma área, o que acontece é uma determinada cultura ocupando sucessivamente diferentes tratos de terra. O rendimento, dadas as condições rudimentares da lavoura, é muito reduzido, geralmente mal dando para cobrir as necessidades do consumo local (Codevale, 1967, p. 102).

Esse tipo de agricultura primitiva, descrita no relatório, é responsável pelo abandono das terras, quando estas apresentam sinais de exaurimento. O avanço das grandes fazendas, por meio da posse de roceiros, a fim de incorporar seus terrenos e sua mão de obra não é problematizado no relatório, passando a impressão de que o "abandono da terra e seu baixo rendimento" é culpa apenas da "ignorância do agricultor", não considerando as características de expropriação em que esses agricultores se encontram (Calixto, 2006; Ribeiro, 2007; Leite, 2010).

Derrubando um trecho de mata ou capoeirão para expansão das pastagens, alguns fazendeiros permitem que os agregados estabeleçam suas roças. Planta-se então o milho, o feijão, a mandioca, ou se fazem ainda outros cultivos de subsistência. Essas roças duram, em média, três anos, quando então se inicia seu abandono, pois as terras já receberam sementes de [capim] colonião, espalhadas pelos homens ou mesmo pelo vento e a gramínea toma posse assenhoreando-se do seu novo domínio. A derrubada se processa mais além, repetindo-se o mesmo processo de rotação de terras (Codevale, 1967. p. 110).

Comumente, o relatório descreve que o problema da região está relacionado às pessoas que vivem no Vale do Jequitinhonha. Ora esses relatórios colocam elas como vítimas, ora como culpadas do processo de subdesenvolvimento presente na região. A população que, ali, é “oprimida pela realidade de seu mundo pequeno, cujos os horizontes não vão muito além daqueles que seus olhos alcançam", seria vítima de um "processo econômico que gerou um conjunto de circunstâncias amesquinhadoras do homem, onde o analfabetismo, a subnutrição crônica e o isolamento são traços dominantes”. E, por conta dessas características, de certa forma, também são responsáveis pelas dificuldades ali existentes (Codevale, 1967).

Oprimido pela realidade de seu mundo pequeno, cujos horizontes não vão muito além de onde seus olhos alcançam. Ignorantes, desinformados, aferrados de verdades que governam as coisas e que sempre prevaleceram como tais, assumem com frequência o comportamento característico dos membros de todo grupo que enfrenta uma dificuldade instransponível (Codevale, 1967, p. 121).

Depois de apresentar as características da agricultura local, o relatório prossegue com informações e análises sobre as características dos recursos naturais da região. Essas características seriam grandes obstáculos para o desenvolvimento agrícola do Jequitinhonha, dessa forma o relatório aborda, como sugestão, um estudo sobre a pedologia da região com orientações de adubação e novos métodos para substituir a rotação de terras, além de manejos para aumentar o rendimento da produção com a realização de um "programa de difusão em larga escala de métodos de racionalização da atividade agrícola", a fim de que a região saia do "estágio de economia da troca e autoconsumo" para a "plenitude da economia de mercado" (Codevale, 1967).

No relatório, a CODEVALE sugere intervenção econômica na região a partir de dois caminhos: o primeiro, baseado no incentivo ao desenvolvimento técnico das atividades que ali já existem, porém, focando no aumento da produtividade; e, o segundo consiste no incentivo ao aumento da infraestrutura social e econômica, a fim de viabilizar o surgimento de novos setores econômicos privados que estariam ligados a atividades urbanas e rurais (Codevale, 1967).

A CODEVALE seria responsável pela condição de facilitadora da atuação de empresas na região, as quais se encarregariam de promover o desenvolvimento em troca de algumas facilidades como a criação de infraestrutura e subsídios fiscais. Apesar de não existir ligações diretas nos textos entre a CODEVALE e a implantação dos maciços florestais na região, ela representou um marco na região que possibilitaria a implantação de diferentes projetos, entre eles monoculturas de café, mineradoras, barragens e, neste caso, as empresas de eucaliptos. 


\section{Narrativas e Eucaliptais}

A delimitação do Vale do Jequitinhonha enquanto área extremamente propicia a receber o plantio dos eucaliptais foi responsabilidade de instituições estaduais e federais como o Instituo Estadual de Florestas de Minas Gerais (IEF) e Instituto Brasileiro de Desenvolvimento Florestal (IBDF), os quais produziram diversos documentos e planos para a expansão dos plantios dos eucaliptais em áreas consideradas propicias à atividade. Dentre estas publicações, há o "Plano especial para o financiamento do reflorestamento em Minas Gerais" e o "Projeto de Distritos Florestais para Minas Gerais", ambos confeccionados em cooperação técnica entre estas instituições.

Esses planos se propunham a delimitar áreas que seriam propícias a implantação de projetos de reflorestamento em Minas Gerais e usavam dois diferentes tipos de narrativas: uma legitimando com base em análises técnicas e outra, em análises sociais e econômicas da região. As análises sociais e econômicas se assemelham com as narrativas produzidas pela CODEVALE, portanto se apresenta aqui, somente, as narrativas referentes as análises técnicas para implantação de projetos de reflorestamento.

Um fator limitante, no processo de expansão dos eucaliptais, era o acesso à terra, visto que, nas regiões onde as indústrias siderúrgicas estavam instaladas, os altos preços inviabilizavam esses investimentos. Os mapeamentos realizados pelo IEF e o IBDF visavam regiões taxadas como "reprimidas economicamente", que dispunham de terras a baixo custo e eram regiões consideradas prioritárias para a homogeneização do desenvolvimento (Calixto, 2016). A implantação dos empreendimentos florestais era pautada, principalmente, pela estagnação econômica da região, cabendo a esses empreendimentos a esperança de salvação econômica (Zimmermann, 2012).

Os planos trazem informações técnicas sobre solo, condições edafoclimáticas, vegetação, recursos hídricos, agrometeorologia, apresentando características locais e elencando possibilidades e limites em relação à implantação de florestas plantadas de eucalipto. Essas florestas deviam ser implantadas nas chapadas, pois são terras que, em sua maioria, eram devolutas do Estado ou tinham um preço reduzido por sua baixa aptidão natural à agricultura. As chapadas são grandes extensões de terras que apresentam uma zona de transição entre o cerrado e a caatinga, sendo o cerrado a vegetação de maior predominância. Assim, os solos são pobres e ácidos e apresentam regime de chuva concentrado nos meses de novembro a fevereiro (Ief, 1975).

Mesmo com características impróprias para a agricultura, como solos pobres e ácidos e regime de chuva concentrado, os eucaliptais clonados em conjunto com as técnicas de adubação se adaptaram bem, o que levou há uma rápida expansão da atividade na região, legitimando cada vez mais a ideia de desenvolvimento que o eucalipto carregava. A primeira empresa que chegou a região gerou 5.000 empregos diretos, potencializando a expansão desses projetos (Calixto, 2006; RIBEIRO, 2007).

As narrativas em torno do Vale do Jequitinhonha se formam criando as condições específicas para implantação do DFVJ. Pois, no contexto do "Vale do Jequitinhonha", uma região do nordeste de Minas Gerais, será construído o enredo que apresenta as diferentes relações existentes nesse território, entre as populações tradicionais, meio ambiente e estruturas econômicas e sociais. Todas essas relações arquitetam uma situação de caos, em que subdesenvolvimento é dominante e que deve ser revertido, no entanto, para isso, diferentes personagens aparecem apresentando análises e contribuições para a resolução desse problema. O Vale do Jequitinhonha é constituído como local de intervenção estatal a partir dessas narrativas. Já, o eucalipto aparece como herói da história, onde ficaria responsável por alterar toda uma dinâmica social, econômica e ambiental.

\section{Considerações Finais}

O presente trabalho procurou entender os processos constituintes da criação do Distrito Florestal do Vale do Jequitinhonha, para isto se propôs a estudar essa formação a partir da metodologia de abordagem cognitiva de análise de 
políticas públicas. Além disso, assim, buscou-se entender mais profundamente os paradigmas e as narrativas que ajudaram a dar origem ao DFVJ.

Essas duas formas de pesquisa se complementam, pois os paradigmas procuram visualizar e compreender as ideias em comum que formuladores de políticas públicas carregam e como essas ideias influenciam os processos de escolha "Problema/Solução". Por conseguinte, as narrativas são utilizadas para identificar como foram pensadas as ações em determinado local, espaço ou tempo, as quais, normalmente, são geradas a partir de estudos de dados secundários e primários, o que não significa necessariamente que são feitas em veracidade ou de forma neutra pelos atores.

Neste estudo de caso, os paradigmas do regime militar foram influenciados fortemente pela Doutrina de Desenvolvimento e Segurança Nacional, cuja forma de desenvolvimento era norteada pelo fortalecimento das indústrias de bens de consumos duráveis, que se estruturaram a partir de grandes investimentos e subsídios para setores como a siderurgia. Essa concepção culmina na criação da política de subsídios para projetos de reflorestamento no Brasil, além de outras ações focadas no desenvolvimento deste setor.

Essa política de subsídios foi responsável pela viabilidade econômica e técnica de monoculturas em diferentes regiões, atingindo, prioritariamente, regiões consideradas estagnadas economicamente e com disponibilidade de terras a baixo custo. De acordo com isso, as narrativas em torno do Vale do Jequitinhonha apresentavam este quadro econômico, sendo uma região esquecida no tempo e, totalmente, dependente de investimentos do Estado para reverter essa situação. Assim, essas narrativas construíram cenários e criaram personagens que legitimaram as diversas ações de desenvolvimento do governo na região.

As duas análises se encontram e podem ser estudadas conjuntamente, visto que as narrativas construídas para a região se apoiam nos paradigmas de desenvolvimento da época, ou seja, priorizam o desenvolvimento econômico em detrimento a outros tipos de desenvolvimento. Também, carregam a ideia de que "cabe a elite tomar os rumos do desenvolvimento do país", onde os projetos de desenvolvimento para a região não desconsideram as características sociais, econômicas, culturais e vontades das populações locais.

As narrativas que foram analisadas por este trabalho representam como os paradigmas influenciam nas escolhas dos problemas e soluções. A construção do Vale do Jequitinhonha, enquanto lugar de extrema pobreza, acontece concomitante ao projeto de desenvolvimento do período militar, onde as bases tradicionais de agricultura camponesa não são viáveis, devendo ser substituídas por complexos agroindustriais que ficariam responsáveis de levar desenvolvimento para a região. Então, as narrativas ficam responsáveis por criar o cenário desastroso do Jequitinhonha e também por propor alternativas, entre elas, a implantação de monoculturas de eucaliptos como resolução desses problemas.

Os agricultores costumam relacionar a chegada dos eucaliptais com a diminuição dos recursos hídricos da região, menor disponibilidade de terra para o cultivo e aumento da migração rural, tendo um pensamento comum que os eucaliptais trouxeram consigo mais problemas do que soluções para a região (Ribeiro \& Galizoni, 2003). O atual desenvolvimento do Jequitinhonha não é responsabilidade dos eucaliptais, mas, sim, da agricultura familiar da região, principalmente, quando as políticas públicas passaram a ser direcionadas às verdadeiras demandas desses grupos.

Como as análises documentais no presente estudo se inclinaram em narrativas relacionadas ao período correspondente de implantação do Distrito Florestal no Vale do Jequitinhonha, evidencia-se a necessidade de se explorar cenários posteriores ao supracitado, identificando-se os elementos e atores que possam elucidar as narrativas que se desenvolveram (e se desenvolvem) atualmente nessa região

\section{Referências}

Brasil. (1966). Lei $n^{\circ}$ 5.106, de 2 de setembro de 1966. 
Brasil. (1971). Presidência da República. I Plano Nacional de Desenvolvimento, 1972-1974. Rio de Janeiro.

Calixto, J. S. (2006). Reflorestamento, terra e trabalho: análise da ocupação fundiária e da força de trabalho no Alto Jequitinhonha, MG. Dissertação (Mestrado em Administração) - Departamento de Economia e Administração, UFLA, Lavras, Brasil.

Coelho, E.C. (2000). Em busca de identidade: o exército e a política na sociedade brasileira. Record.

Codevale. (1967). Pré-diagnóstico do Vale do Jequitinhonha, v. I e II. Edição do Governo de Minas Gerais, Belo Horizonte.

ESG. (1976). Manual Básico da Escola Superior de Guerra. Rio de Janeiro: Estado-Maior das Forças Armadas: Escola Superior de Guerra: Departamento de Estudos.

Fagundes, A. C. (2014). Do golpe à ditadura: a Doutrina de Segurança Nacional e a construção do regime militar. Opsis, 14(1), 60-78.

Fico, C. (2004). Além do golpe: versões e controvérsias sobre 1964 e a ditadura militar. Record.

Grisa, C. (2011). As ideias na produção de políticas públicas: contribuições da abordagem cognitiva. In: Bonnal, P. \& Leite, S. P. Análise comparada de políticas agrícolas - uma agenda em transformação. Mauad Editora.

Grisa, C. (2018). Mudanças nas políticas públicas para a agricultura familiar no Brasil. Raízes: Revista De Ciências Sociais e Econômicas, 38(1), 36-50.

Hall, P. (1993). Policy Paradigms, Social Learning and the State: The Case of Economic Policymaking. Comparative Politics, 25, $275-296$.

IBGE. (1997). Diagnóstico ambiental da Bacia do Rio Jequitinhonha: diretrizes gerais para a ordenação territorial. Salvador: IBGE.

IEF. (1975). Projeto de Distritos Florestais para Minas Gerais. Estudos Básicos, v.1. I e II. Edição do Governo do Estado de Minas Gerais, Belo Horizonte.

Lam.ba, J.R., Silvestre, H. C., \& Correia, A. M. As teorias do processo político na avaliação das políticas públicas brasileiras: aplicações e agenda de pesquisa. Revista Brasileira de Informação Bibliográfica em Ciências Sociais, 88, 1-31.

Leite, A. C. G. (2010). A modernização do Vale do Jequitinhonha mineiro e o processo de formação do trabalhador "boia fria" em suas condições regionais de mobilidade do trabalho. Dissertação (Mestrado em Geografia) - Departamento de Geografia da Faculdade de Filosofia, Letras e Ciências Humanas da Universidade de São Paulo, Brasil.

Lopes, B. R. V. (2015). Função da "análise de narrativa política": para se entender (e problematizar) mudanças institucionais e de paradigmas políticos. IN: Anais... V Seminário Discente do Programa de Pós-Graduação em Ciência Política, Departamento de Ciência Política, da Faculdade de Filosofia, Letras e Ciência Humanas da Universidade de São Paulo, Brasil.

Muller, P. \& Surel, Y. (2002). Análise das políticas públicas. EDUCAT.

Niederle, P., Grisa, C., Picolotto, E. L., \& Soldera, D. (2019). Narrative Disputes over Family-Farming Public Policies in Brazil: Conservative Attacks and Restricted Countermovements. Latin American Research Review, 54(3), 707-720.

Pereira, A.S. et al. (2018). Metodologia da pesquisa científica. UFSM.

Ribeiro, E. M. et al. (2007). Agricultura familiar e programas de desenvolvimento rural no Alto Jequitinhonha. Revista de Economia e Sociologia Rural, 45(4), $1075-1102$.

Ribeiro, E. M. \& Galizoni, F. M. (2003). Água, população rural e políticas de gestão: o caso do vale do Jequitinhonha, Minas Gerais. Revista Ambiente e Sociedade, 1(1), 129-146.

Rodrigues Neto, D. D., \& Barcelos, M. (2020). Histórias na agenda: uma aplicação do "Narrative Policy Framework". Revista De Administração Pública, 54(6), 16-32.

Silva, M. N. \& Anjos, F. S. (2020). A expansão da soja no município de Jaguarão/RS: análise das percepções através da abordagem narrativa. Revista de Economia e Sociologia Rural, 58(3).

Soares, G. A. D. (1994). O golpe de 64. In: Soares, G. \& D’araújo, M. C. 21 anos de regime militar: balanços e perspectivas. Rio de Janeiro: Fundação Getúlio Vargas.

Teixeira, M., Aráujo Fernandes, A. S., Zuccolotto, R., \& do Nascimento, A. B. F. M. (2020). La política de inacción del gobierno brasileño ante la pandemia de COVID-19. GIGAPP Estudios Working Papers, 7, 533-554.

Vasconcelos, F. C. F. (2018). As narrativas da FAO sobre Segurança Alimentar: uma análise sobre a convivência de paradigmas políticos conflitantes. Master's thesis, Universidade Federal do Rio Grande do Sul, Brasil).

Zimmermann, C. L. (2012). Monocultura e transgenia: impactos ambientais e insegurança alimentar. Juris Plenum Ouro, 24, 20. 